\title{
O CONSUMO DE CARNE, A CRISE CLIMÁTICA E A SAÚDE MUNDIAL PELA PERSPECTIVA DA EDUCAÇÃO AMBIENTAL COMPLEXA
}

\author{
Rhuann Carlo Viero Taques ${ }^{1}$ \\ Patricia Neumann ${ }^{2}$ \\ Thiago Francisco Costa Solak ${ }^{3}$
}

Resumo: O objetivo deste artigo é discutir a relação entre o consumo de carne, a crise climática e a saúde mundial pela perspectiva da Educação Ambiental Complexa. O método foi bibliográfico e considerou-se a pandemia causada pelo COVID-19. Os resultados apontam que o consumo de carne como uma das causas diretas do surgimento de pandemias e consequente adoecimento da humanidade. Considera-se que a Educação Ambiental Complexa proporciona uma perspectiva de compreensão sistêmica e ampla desta problemática e propõe a construção possível de uma sociedade sustentável.

Palavras-chave: Complexidade; Pandemia; COVID-19, Transdimensional.

Abstract: The objective of this paper is to discuss the relation among meat consumption, climate crisis and world health based on Complex Environmental Education perspective. Method was bibliographic and the pandemic caused by COVID-19 was considered. Results were meat consumption is directly one of causes for pandemics and consequently humanity sickness. We consider Complex Environmental Education offers a systemic and wide perspective of this problem and it proposes a possible construction of a sustainable society.

Keywords: Complexity; Pandemic; COVID-19; Transdimensional.

\footnotetext{
1 Universidade Estadual do Centro-Oeste. E-mail: rhuanntaques@gmail.com, Link para o Lattes: http://lattes.cnpq.br/8250506102496790

2 Universidade Estadual do Centro-Oeste. E-mail: souhumanista@gmail.com. Link para o Lattes: http://lattes.cnpq.br/9354677539847614

${ }^{3}$ Universidade Estadual do Centro-Oeste. E-mail: thiagosolak@gmail.com. Link para o Lattes: http://lattes.cnpq.br/1897657380688684
} 


\section{Introdução: o ambiente transdimensional}

A Educação Ambiental (EA), em seu princípio, adotava uma percepção de ambiente atrelada à natureza, voltada para a sua conservação, tendo a preservação como algo ligado exclusivamente à biodiversidade. $\mathrm{O}$ ambiente, neste sentido, era compreendido em seus aspectos naturais como água, ar, solo e os seres vivos. Contudo, a partir de discussões acerca desta concepção nas últimas décadas, ao conceito de ambiente se incorporaram as dimensões humanas e sociais. Atualmente, nas Diretrizes Curriculares Nacionais, bem como na comunidade científica da área, é comum a perspectiva de meio ambiente oriunda das inter-relações da sociedade e natureza, isto é, socioambiental, uma vez que se entende que natureza e sociedade estão numa relação muito próxima, em que uma interfere na outra, sendo a mesma lógica de exploração capitalista tanto da natureza quanto do ser humano (CARVALHO, 2008).

Esta visão de meio ambiente, contudo, não é unânime nem é a mais difundida quando se trata da prática na Educação Básica. Nela, ainda predomina a visão de meio ambiente apenas como natureza e recursos naturais. Temos, então, uma discrepância entre o que se tem produzido cientificamente, o que a legislação brasileira em EA orienta e o que se tem praticado nas escolas. Isto não apenas quanto à noção de meio ambiente, mas também quanto ao próprio modo com que a EA deve ser trabalhada (ANTONIO; NEUMANN, 2019).

Hoje, é inviável e irrazoável pensar e discutir uma EA desconectada da relação sociedade-natureza-cosmos. É neste contexto que se insere a EA complexa (NEUMANN et al., 2019), a qual temos como a principal base os estudos de Edgar Morin (MORIN, 2011; 2013; 2015). A EA complexa aprofunda as dimensões que têm sido discutidas em outras abordagens como a noção de ambiente e, neste sentido, parte da noção de ambiente transdimensional. Isto pois, ao se referir ao ambiente, é trazida a pluralidade de dimensões como a física, a ecológica, a biológica, a humana e a cósmica. De acordo com Morin (2011) complexidade (complexus) significa o que foi tecido junto, ou seja, o que é impossível de estar desconectado. Dentro de cada dimensão existem várias outras dimensões. Por exemplo, na humana, temos a dimensão social, política, econômica, histórica, ética, estética, espiritual, dentre outras. Salientamos que a EA complexa defende uma noção mais ampla de ambiente, a qual atribui igual status ontológico a todos os seres animados e inanimados e, consequentemente, a todas as dimensões com as quais estes seres se relacionam, sem priorizar uma em detrimento de outras. Além disso, a forma como se compreende estas dimensões é peculiar, pois ao entender a realidade como complexa, nada pode ser desconsiderado quando se pensa em solucionar um problema. Todas as dimensões estão presentes e atuantes, bem como elas dialogam de modo transrelacional. 
Afirmamos também este termo: transrelacional. Trata-se de uma forma complexa de compreender a viver as relações e suas dimensões. Partimos de Morin (2015) que salienta que o todo tem em si suas partes e a parte tem em si o todo. Isto vale para tudo o que possamos conhecer da realidade. Como exemplo, temos a célula, a parte, que participa do todo que é o organismo. A célula está no organismo, mas o organismo, que é o todo, enquanto o DNA, também está na célula. Outro exemplo: o sujeito é a parte de um grupo social que é o todo, participa deste todo, mas o social também participa do sujeito, quando este leva em conta os outros seres em suas decisões e ações. São dimensões que transitam uma com a outra, que formam e transformam-se no contato. As dimensões não estão paradas, mas em constante vir a se tornar algo, mesmo que imperceptível à consciência num certo nível de realidade. $\mathrm{A}$ natureza e o cosmos não param de se movimentar e os seres que fazem parte do cosmos também estão em movimento, sejam eles animados ou inanimados. Por isso, esta noção de transdimensão: dimensões em constante vir a ser, em que uma penetra na outra e ambas modificam. As relações destas muitas dimensões são transrelacionais.

Os termos transdimensional e transrelacional estão conectados ao significado do termo transdisciplinar que, conforme Nicolescu (1999; 2019), já tem sido elaborado desde os anos 1970 e que se trata de uma abordagem científica, cultural, espiritual e social. A abordagem trans se refere ao que está entre, através e para além das disciplinas em que o principal objetivo é a compreensão do mundo presente pela unidade do conhecimento. Falar de transdisciplinaridade e, consequentemente, acrescemos, de transdimensões e transrelações, é falar de níveis fluídos de realidade. Trata-se de partir de que os níveis de realidade são níveis de conhecimento dos objetos e sujeitos; de que o sujeito está conectado com o objeto, isto é, o sujeito está conectado com aquilo que conhece e a neutralidade e objetividade rigorosas são um equívoco. Equívoco este, salientamos, que foi tomado como a única realidade possível dentro da modernidade. Em outras palavras, a modernidade tratou a realidade como simples. A perspectiva transdimensional, transrelacional e transdisciplinar trata a estrutura da realidade como complexa, mutável e singular a cada momento.

A complexidade, segundo Moraes (2019), é uma formulação ontológica e, como tal, traz novas aberturas e possibilidades lógicas, metodológicas e epistemológicas. Ela está diretamente relacionada a uma visão de ser humano que é uma parte do todo e que também tem em si este mesmo todo. Trata-se de um ser humano incluso no mundo, que o transforma e que é transformado por ele. Desta identidade entre ser humano e mundo, colapsa a visão de ser humano superior a outros seres animados e inanimados e derroca a posição de um ser humano que explora e degrada o meio que vive. O ser humano, então, é um ser em aberto, em construção e desconstrução, uno com o todo, produtor de relações das quais recebe as consequências de sua existência com as muitas realidades possíveis em micros e macros níveis. 
Assim, compreender o ambiente só em relação à natureza física é insuficiente e ineficiente para resolver problemas, pois os problemas não são fruto de uma única dimensão (não são simples), mas de muitas dimensões e relações que são construídas pelos próprios sujeitos. A realidade não está fragmentada em si mesma, embora pareça estar quando vista apenas de uma perspectiva simples. Neste sentido, então, a partir de um estudo bibliográfico sob olhar da EA Complexa e, em especial, da noção de realidade transdimensional, propomo-nos a pensar e discutir a relação entre o consumo de carne, a crise climática e a saúde pública, levando em consideração o momento histórico e político proporcionado pela atual pandemia do COVID-19.

\section{A complexidade entre surtos epidemiológicos e o consumo de carne}

Existe apenas uma espécie responsável pelo estabelecimento de surtos epidemiológicos, inclusive a atual pandemia causada pelo COVID-19: a humana (SETTELE et al., 2020). O colapso socioambiental, fruto desta situação, não é um evento isolado, mas um processo em curso (RIPPLE et al., 2017), marcado por um período de instabilidade em todas as complexas esferas intrínsecas à existência humana.

Doenças como COVID-19 são causadas por microorganismos que infectam nosso corpo - com mais de $70 \%$ de todas as doenças emergentes que afetam pessoas originárias da vida selvagem e de animais domesticados. As pandemias, no entanto, são causadas por atividades que levam um número crescente de pessoas a entrar em contato direto e geralmente entram em conflito com os animais que carregam esses patógenos (SETTELE et al., 2020).

A atual pandemia que acomete todo o nosso planeta, de acordo com um recente estudo da Universidade Estadual de Campinas (MARQUES, 2020), intervém em um momento histórico e político sendo resultado de três crises estruturais de nossas sociedades contemporâneas. Estas convergem sinergicamente à insustentabilidade ambiental e são: a emergência climática, a aniquilação em curso da biodiversidade e o adoecimento coletivo da humanidade.

A partir da perspectiva da EA complexa e o conceito de ambiente transdimensional, é possível perceber que surtos epidemiológicos e, em especial, a pandemia do COVID-19, estão diretamente relacionados com o hábito humano de consumir carne em suas dietas. Isto porque esta prática alimentar, da forma como tem sido gerenciada e realizada, por intermédio do desmatamento desenfreado e pela expansão descontrolada da agricultura, justamente é um dos fatores responsáveis pelo estabelecimento de crises sistêmicas que ameaçam a humanidade. 
O desmatamento possui relação direta com a aceleração no ritmo de epidemias e pandemias no mundo. Um artigo publicado pelo Fórum Econômico Mundial, entidade que uma vez por ano reúne, na Suíça, os líderes empresariais e políticos do mundo, mostrou que $31 \%$ dos 12.012 surtos de doenças e epidemias entre 1980 e 2013 estão ligados, diretamente, a ambientes que foram desflorestados (WEF, 2020). Isto representa, aproximadamente, 44 milhões de casos particulares que acometem todos os países do globo terrestre. Este mesmo artigo ressalta que a conectividade global provinda de viagens e comércios também possui sua parcela de responsabilidade, porém, os vínculos desta problemática com o desmatamento e suas consequências são as mais impressionantes. Em 2015, o IPEA fez um alerta semelhante ao revelar que, para cada $1 \%$ de Floresta Amazônica derrubada, há um aumento de $23 \%$ na incidência de casos de malária e $9 \%$ na incidência de casos de leishmaniose (PAULINO, 2015).

Em grande parte da história, as doenças infecciosas foram as maiores responsáveis pela mortalidade da espécie humana no mundo (PENA, 1998). Porém, este quadro declinou em meados do século $X X$, a partir da adoção de medidas relacionadas à higiene pessoal, ao saneamento básico e à revolucionária descoberta da penicilina. A partir dos anos 1960, contudo, doenças infecciosas de origem animal ganharam vigor e atraíram atenção da comunidade cientifica global (ABRAMOVAY, 2019). O que se percebeu foi que o contato da civilização humana para com os ambientes florestais permitiu com que vetore ${ }^{4}$ que antes não a atingiam, passassem a atingi-las. Esta situação levou à publicação de um relatório acerca das ameaças microbianas à saúde dos EUA, no ano de 1992 (LEDEBERG, et al., 1992), que identificou que 75\% das doenças infecciosas emergentes, ou seja, aquelas cuja incidência em humanos estavam a aumentar nos últimos anos, eram zoonoses, as quais poderiam ser transmitidas por animais (Ibid., 1992).

Portanto, o contato da civilização humana com animais exóticos pelo compartilhamento de nichos ecológicos e a consequente repartição dos recursos e condições disponíveis fez com que diversas doenças acometessem nossa espécie como, por exemplo, a AIDS que teve sua origem de primatas (DIAMOND, 1992), a SARS que teve sua origem em gatos-da-algália; o Ebola e o atual COVID-19 que tiveram suas origens pela ingestão de morcegos (WEF, 2020). O desmatamento, assim, além de ser ameaçador à biodiversidade, tornou-se ameaçador à saúde e à vida humana.

Um estudo revelou que, até o ano de 2050, se planeja a construção de aproximadamente 25 milhões de quilômetros de estradas pavimentadas, o suficiente para dar 600 voltas ao redor do planeta terra (RIPPLE et al., 2017). Cerca de 90\% destas estradas serão construídas em países em desenvolvimento, frequentemente em áreas florestais tropicais ou

\footnotetext{
${ }^{4}$ Os vetores são os veículos de transmissão do agente causador da doença, ou seja, é o organismo capaz de transmitir o ser vivo que realmente desencadeará uma enfermidade (PENA, 1998).
} 
subtropicais com grande biodiversidade e valor ambiental por seus serviços ecossistêmicos (Ibid., 2017). Este cenário fica ainda mais grave quando Barber e seus colaboradores (2014) indicam que, na Floresta Amazônica, por exemplo, para cada três quilômetros de estrada legal, há um quilômetro de estrada ilegal, justamente pela facilidade de acesso. Desta maneira, as estradas e o consequente desmatamento se tornam verdadeiros vetores de transmissão de doenças infecciosas emergentes.

Alagmir e seus colaboradores explicitam que grande parte da construção de estradas, em áreas florestais, de todo mundo, estão relacionadas à apropriação territorial como mecanismo de ocupação de terra para agropecuária. No planeta Terra vivem cerca de 8 bilhões de seres humanos. Todos os anos, abatem-se, aproximadamente, 70 bilhões de animais terrestres e uma quantidade infinitamente maior de animais aquáticos para o consumo alimentar (FAOSTAT, 2013). Os alarmantes impactos sociais e ambientais advindos desta prática são inúmeros, pois cada um desses animais precisa de determinada quantidade de terra, água, alimento e energia; produz quantidade expressiva de dejetos e emite, direta e indiretamente, poluentes que serão dispersados pelo solo, ar e água. Estima-se que, aproximadamente, $30 \%$ das terras do todo planeta, área equivalente a todo o continente africano, seriam destinadas a pastagens para criação de animais ao abate (SCHUCK; RIBEIRO, 2015). No Brasil, cerca de $80 \%$ da área desmatada da Floresta Amazônia se dá pela utilização territorial de atividades pecuárias (BARBOSA, 2019). Quase metade das terras não gélidas da terra - $75 \%$ das áreas agrícolas - são destinadas para pastagem ou produção de rações para animais que serão abatidos (KOLBERT, 2015).

Este uso da terra é insustentável. A degradação da vegetação, por meio do desmatamento e compactação do solo pelo pisoteamento do gado, compromete a absorção de água e as trocas gasosas entre solo/atmosfera (Ibid., 2015). Aproximadamente, $50 \mathrm{mil} \mathrm{km}^{2}$ de solo se perdem todo ano no nosso planeta pelo déficit nutricional causado pela ausência de cobertura vegetal, serapilheira e microbiota destas atividades (NELLEMAN et al., 2009). Diante desta complexidade, o consumo alimentar de carne da forma como é realizado, além de contribuir para um estilo de vida insustentável, contribui para o estabelecimento de surtos epidêmicos por meio do desmatamento e, além disto, intensifica determinados fatores inescusáveis, responsáveis pela crise climática contemporânea.

Acerca desta crise climática em que vivemos, é um fato de que ela cresce a cada dia, fruto, principalmente, da emissão de gases de efeito estufa (GEE) na atmosfera terrestre. Diante disto, o historiador Luiz Marques (MARQUES, 2020) esclarece que, em abril de 2017, um grupo de cientistas lançava a obra The Climate Turning Point. Ela norteou a criação, por diversas lideranças científicas e diplomáticas, da Missão 2020. Esta definia metas básicas, inclusive relacionadas ao uso das terras pela indústria pecuária, de modo a tornar declinante, a partir de 2020, a curva das emissões de gases de 
efeito estufa para colocar o planeta numa trajetória consistente com o Acordo de Paris. Porém, dois meses antes de chegarmos a 2020, Ge et al., (2019) realizaram um balanço acerca do cumprimento das metas estabelecidas e afirmaram que, na maioria dos casos, a ação foi insuficiente ou o progresso foi nulo. De acordo com estes autores, a última vez em que a Terra teve uma concentração comparável de dióxido de carbono, na atmosfera, foi entre 3 e 5 milhões de anos atrás. A temperatura, naquele momento, era de $2^{\circ} \mathrm{C}$ a $3^{\circ} \mathrm{C}$ superior e o nível do mar estava, aproximadamente, 20 metros acima do atual.

Contudo, estudos comprovam que cerca de $40 \%$ das emissões de GEE em todo o mundo provêm de atividades relacionadas à pecuária (SCHUCK; RIBEIRO, 2015). No Brasil, um relatório do Sistema de Estimativa de Emissões de Gases de Efeito Estufa (SEEG) constatou que a criação de animais para o consumo alimentar era responsável por cerca de $84 \%$ das emissões destes gases (SEEG, 2015). Por conta da flatulência (oriunda da fermentação entérica dos ruminantes) e volatilização decorrente da deposição de dejetos dos animais, os gases metano e óxido nitroso acabam por ser de 20 e 300 vezes, respectivamente, mais potencialmente poluidores que o dióxido de carbono (KATAOKA et al., 2019). Acerca deste gás, Schmidinger (2012) destaca que a produção de um quilo de carne bovina é responsável por emitir quantidade correspondente à gerada por um carro que percorre 800 quilômetros e, desta forma, a pecuária - atividade oriunda do consumo de carne - se torna responsável por $57,5 \%$ da emissão total e global de $\mathrm{CO}^{2}$, o principal gás causador do efeito estufa na atmosfera terrestre (OLIVERA et al., 2011).

O efeito estufa é responsável pelo aumento da temperatura média global. De acordo com a Administração Nacional da Aeronáutica e Espaço (NASA, 2020), a temperatura média do ano de 2020 já cravou, globalmente, $1,51 \mathrm{C}^{\circ}$ acima do normal e, desta forma, "o aquecimento global é uma arma apontada contra a saúde global" (MARQUES, 2020, p. 1). Esta temperatura mais alta torna mais fácil o estabelecimento de surtos epidemiológicos, já que os micro-organismos patógenos se adaptam melhor ao calor (PECL et al. 2017). Além disto, à medida em que o planeta aquece, os animais tendem a migrar para os polos para fugir do alto calor. Neste movimento, entram em contato com ambientes incomuns, o que favorece o encontro de novos patógenos e hospedeiros que podem ser prejudiciais à saúde pública.

Além da emergência da crise climática global, o outro pilar em que se consolidou a atual pandemia do COVID-19, e que é grande fruto do consumo de carne, é o da aniquilação da biodiversidade. Schuck e Ribeiro (2015) destacam que vivemos a sexta grande extinção em massa, sendo, porém, a primeira causada por uma espécie: Homo sapiens. Os autores relatam, ainda, que, em apenas duas gerações, o número de indivíduos de diversas populações de mamíferos, répteis, anfíbios e peixes caiu pela metade por consequência da perda de habitats e perturbação de ciclos biogeoquímicos causados pela indústria pecuária. Uma pesquisa realizada pelo Ministério do Meio Ambiente, recentemente, também demonstrou que este setor é o principal 
responsável pela extinção de espécies animais e vegetais em absolutamente todos os biomas brasileiros (MMA, 2020), ficando acima de problemáticas como a caça ilegal, a urbanização, a mineração, as queimadas e a produção de energia.

O adoecimento coletivo da humanidade não provém diretamente do consumo de carne apenas por meio de surtos epidemiológicos ou pela emergente crise climática, mas "hoje, a maioria das zoonoses está ligada à criação e consumo de animais" (SCHUCK; RIBEIRO, 2015, p. 31). Grace et al., (2012) destacam que cerca de 2,4 bilhões de seres humanos, todos os anos, sofrem de infecções por doenças provenientes de porcos, galinhas e bois, seja pela proximidade ou ainda pela alimentação destes. Por conta do manejo inadequado e estresse agudo sofrido por estes animais em seus ambientes cativos, a susceptibilidade a infecções e doenças é bastante alta (EISLER et al., 2014). Por este motivo, doses de antibióticos e outros fármacos como quimioterápicos, por exemplo, são aplicados diariamente para que estes possam se prevenir de doenças e sobreviver em ambientes precários até o momento do abate (SCHUCK; RIBEIRO, 2015). Diversos estudos indicam que a utilização de antibióticos em larga escala na indústria pecuária é responsável pelo surgimento e prevalência de cepas bacterianas a determinados medicamentos como a oxitetraciclina, eritromicina e vancomicina, eficazes no combate a microorganismos como Salmonella e Campylobacter (JACKSON et al., 2004; SAPKOTA et al., 2011; GRACE et al., 2012; SCHUCK; RIBEIRO, 2015). Além disto, resíduos de antibióticos presentes nos dejetos destes animais atingem lençóis freáticos e cursos d'água, de modo que 95\% das águas superficiais brasileiras estão contaminadas (MALHEIROS; SILVA, 2009). Estes xenobióticos ${ }^{5}$, contudo, não podem ser eliminados por meio dos tratamentos convencionais de água e, ao chegar ao corpo humano, por meio da ingestão, são metabolizados formando intermediários reativos que podem ser prejudiciais à saúde (GONÇALVES et al., 2014).

Percebe-se, diante disto, que os três pilares destacados por Marques (2020) como crises estruturais na relação entre as sociedades hegemônicas contemporâneas e o sistema Terra: a emergência climática, a aniquilação em curso da biodiversidade e o adoecimento coletivo da humanidade e que, por sua vez, propiciam o surgimento de surtos epidemiológicos como o COVID-19, têm transrelações com o hábito de consumir carne em dietas alimentares. Salientamos que a compreensão da complexidade envolvida no consumo da carne exige árduo esforço, visto que conceber a totalidade de como este tipo de consumo se relaciona a uma pandemia, por exemplo, não é desejo de nosso sistema financeiro e econômico predominante. Além disto, a nossa própria existência em meio a uma crise socioambiental está marcada pela já comentada segmentação da relação sociedade/natureza.

Esta segmentação pode ser considerada herança de um paradigma

\footnotetext{
${ }^{5}$ Compostos químicos estranhos a um organismo ou sistema biológico.
} 
surgido e estabelecido em meados do século XVII: o racionalismo científico, que tinha por objetivo conduzir a humanidade à procura da verdade absoluta por meio da ciência. Deste modo, obtiveram, como resultado exclusivo, uma única racionalidade sustentada pelo realismo científico (FEYERABEND, 2011). Este tem implicações socioambientais diretas, já que determina o que há de específico no ser humano por exclusão da ideia de natureza, separando o sujeito do objeto, a finalidade da causalidade, a teoria da prática e demais dicotomias. De acordo com Morin (2013), o paradigma da modernidade obedece, ainda, a um outro mais antigo: o da simplificação. Este, diante de qualquer complexidade conceitual (sociedade/ambiente, homem/natureza etc) impede que se concebam as (inter)relações, (inter)retroações e as (inter)implicações entre as partes para que se compreenda o todo. Ainda, segundo o autor, o paradigma complexo permite a conjunção das esferas que constituem determinada problemática e está, aos poucos, sendo inscrito na cultura científica. Diante disto, a emergência pela percepção transdimensional do ambiente se faz mais que necessária para a construção de um presente e um futuro com equidade social e ambiental a partir da equidade ontológica.

De acordo com Morin (2015), o paradigma da modernidade está inscrito culturalmente e é constituído de princípios supralógicos de organização do pensamento que governam a visão das coisas e do mundo sem que os sujeitos tenham consciência disto. Dentro deste contexto, muito se fala que o consumo da carne é fruto cultural e, assim como qualquer hábito, foi incorporado no paradigma capitalista por repetição, ao longo do tempo. Joy (2014) denomina este hábito alimentar de 'carnismo' e trata-o como uma matriz psicológica, um sistema de pensamento, que serve como uma lente pela qual (não) se percebe as problemáticas que dele sucumbem. Mas para além disto, em uma sociedade capitalista neoliberal, que possui suas influências que transpassam fronteiras voláteis de diversas culturas, o hábito de comer carne se torna não apenas expressão cultural, mas também pontos de conexão entre os interesses da economia e sua influência sobre a política (KATAOKA, et al, 2019).

Carne é mercadoria e, portanto, gera o acúmulo de capital. Dito isto, percebe-se que há um constante incentivo no que diz respeito ao consumo de carne, principalmente das mídias sociais. De acordo com Kataoka et al. (2019), este interesse muito pouco se preocupa com a nutrição ou saúde dos sujeitos, apesar de se apropriarem deste discurso por meio da racionalização, o que induz os menos avisados a erros e ilusões ${ }^{6}$. Segundo Duarte (2008), a indústria pecuária é abençoada por uma lógica de mercado capitalista e hiper consumista que se faz cega à complexidade de seus impactos socioambientais. Esta lógica está subjugada nas mãos de poucos latifundiários. No Brasil, $4,5 \%$ dos proprietários de fazendas possuem $91 \%$ das terras (Ibid., 2008). Diante disto, grandes empresas de processamento e distribuição do agronegócio que, por conta do seu acúmulo de capital, acabam por ter

\footnotetext{
6 Ver Morin (2015).
} 
condições de explorar o meio ambiente e estender sua influência ao poder público. Brey et al. citados por Pinheiro, De Luca e Vasconcelos (2016, p. 397) afirmam que

As organizações são capazes de tudo que estiver ao alcance para diminuir as incertezas, minimizar as dependências externas e aumentar os recursos de que precisam. (...) Um dos procedimentos para minimizar as dependências externas é possuir vínculos políticos, pois é o governo que intervém nas políticas econômicas e públicas do país.

A indústria pecuária, portanto, adquire constantes subsídios governamentais conquistados por meio de lobistas e de uma bancada pecuarista vitalícia no poder legislativo e judiciário (DUARTE, 2008). Desta forma, obtém alterações na legislação para obter o aval necessário para a intensificação dos processos de exploração ambiental (KATAOKA et al., 2019). Dentro disto, é relevante salientar que não há alimento mais antieconômico que a carne. São necessárias aproximadamente 20 calorias de alimentos vegetais para a produção de apenas uma caloria de carne. É necessário dar ao bezerro, boi ou porco, aproximadamente $20 \mathrm{~kg}$ de alimentos de origem vegetal para produção de menos de $1 \mathrm{~kg}$ de carne. Recupera-se cerca de $5 \%$ do que se investe e cria-se um enorme déficit calórico e um maior ainda desperdício de alimentos vegetais que poderiam estar a ser ofertados à população (DUARTE, 2008).

Essa ineficiência produtiva de proteínas da carne bovina aumenta o impacto ambiental de dietas baseadas no consumo elevado de carne, assim como provoca um aguçamento de problemas socioeconômicos, ao necessitar de maiores extensões de terra para sua produção, levando ao seu encarecimento e escassez, pelo fato de a maior parcela de grãos e cereais ser destinada à pecuária. Somam-se a isso outros impactos ambientais provocados pela produção dos animais de corte, tais como desmatamento, consumo elevado de água e emissão de gases causadores do efeito estufa (PRADO, 2011, p. 12).

Diante disto, percebe-se que as implicações socioambientais do predatório consumo de carne, inclusive na saúde humana, são as mais diversas. É preciso repensar na subjugação dos animais em que os hábitos alimentares das sociedades históricas se fundamentaram. Morin (2011) também compreende que esta subjugação é complexa e, assim, é acompanhada da dominação do território natural, florestas, lagos e rios, 
controlados e explorados pelo ser humano. Surge, a partir disto, regras sociais paradigmáticas que o autor denomina de eco-organizadoras, partindo de um controle antropossocial sistemático sobre todas as esferas atreladas ao ambiente. Salientamos, mais uma vez, a necessidade de perceber a problemática de surtos epidemiológicos e consumo de carne e suas interrelações com outras esferas políticas e econômicas, a partir de uma compreensão de meio ambiente transdimensional.

Para isto, acordamos com Morin (2015) de que se faz necessária uma reforma planetária das mentalidades. A EA complexa, neste sentido, permite ao sujeito desenvolver a aptidão de contextualizar e de globalizar a relação das partes de determinada problemática para com o seu todo e vice-versa. Não podemos ser reducionistas novamente e pensar que apenas parar o consumo da carne vai solucionar os problemas sociais, ambientais e de saúde pública aqui explicitados e, como corrobora Kataoka et al., (2019), precisamos ampliar a consciência de que o consumo da carne sustenta um modelo de sociedade contrário à sustentabilidade em frente à crise socioambiental em que vivemos.

Como educadoras(es) ambientais, cabe-nos difundir ideias, reflexões e soluções no intuito de elucidar e fomentar o desenvolvimento da complexidade para, com isso, construir relações socioambientais saudáveis. Neste escopo, crises também têm sua relevância, no sentido de serem base para a construção de um tipo de pensamento complexo, "pois exigem novas estratégias, novas ações para novas saídas de um sistema, já falido. É um eterno repensar, reflexionar com e no meio em que o sujeito está inserido, pois não há certezas, nem verdades" (BÚRIGO, 2001, p. 5).

\section{Considerações Finais}

Vimos que o consumo de carne da forma que tem sido realizado, desde a produção, industrialização até o consumo propriamente dito, acomete dimensões ambientais, sociais, políticas, econômicas, éticas, raciais, culturais, dentre outras. No atual cenário global em que nos encontramos, sua implicação direta, associada ao desmatamento, na saúde pública diz muito a respeito de como o paradigma capitalista busca desconstruir sociedades sustentáveis frente à crise climática e de saúde mundial.

Diante do desafio e das expectativas em deslindar as transrelações e retroações entre o consumo de carne, a crise climática e a saúde mundial, em meio ao momento em que vivemos por conta da atual pandemia do COVID-19, percebemos que a EA complexa é capaz de proporcionar uma visão que, ao partir do conceito de meio ambiente como transdimensional, é sistêmica e aberta. Aberta no sentido de favorecer possibilidades novas de interpretação e compreensão de múltiplas realidades. A concepção transdimensional abarca as mais diversas esferas concernentes à existência humana e não humana no planeta e para além dele, no cosmos. Assim, as ações antrópicas sobre o mundo refletem, sem dúvida alguma, à própria sociedade. 
Por fim, a análise da implicação do consumo de carne nas mudanças climáticas e nas crises de saúde mundial partem de uma tentativa de escapar à alternação entre, por um lado, o pensamento das partes que só vê os elementos desconectados entre si e, por outro lado, o pensamento que só vê o todo. Desta forma, consideramos que esta discussão é uma das possíveis respostas, no sentido de compreensão, das problemáticas aqui transrelacionadas, bem como aponta para um caminho de intervenção, ou seja, de que é preciso pensar e construir, agora, um novo modo de vida para que possamos continuar a habitar este planeta. Caso contrário, é provável que sejamos nós a próxima espécie em extinção.

\section{Referências}

ABRAMOVAY, R. Amazônia: por uma economia do conhecimento da natureza. São Paulo: Elefante. 2020.112p.

ALAGMIR, M.; CAMPBELL, M. J.; SLOAN, S.; GOOSEM, M.; CLEMENS, G.R.; MAHMOUD, M.I.; LAURANCE, W.F. Economic, Socio-Political and Environmental Risks of Road Development in the Tropics. Current Biology, v. 27, p. 1130-1140, 2017.

ANTONIO, J.M.; NEUMANN, P. A Educação Ambiental nas Diretrizes Curriculares: apontamentos à formação de professoras(es). Anais do XVII Encontro Paranaense de Educação Ambiental. XVII EPEA, 2019. Universidade Estadual de Londrina. Anais do XVII Encontro Paranaense de Educação Ambiental, 2019, p. 1-12. Disponível em: $<$ https://periodicos.unifesp.br/index.php/revbea/article/view/10546/7706>. Acesso em: 09 mai. 2020.

BARBER C.P.; COCHRANE, M.A.; SOUZA, C.M.; LAURANCE, W.F. Roads, deforestation, and the mitigating effect of protected areas in the Amazon. Biology Conservation v. 177, n. 1, p. 203-209, 2014.

BARBOSA, C. Pecuária é responsável por $80 \%$ do desmatamento. Belém do Pará: Brasil de Fato, c2019. Disponível em: $<$ https://www.brasildefato.com.br/2019/09/05/pecuaria-e-responsavel-por-80-dodesmatamento-na-amazonia-afirma-pesquisadora>. Acesso em: 28 abr. 2020.

BREY, N.K.; CAMILO, S.P.O.; MARCON, R.; ALBERTON, A.A.A. A estrutura de propriedade das corporações: conexões políticas a partir da dependência de recursos. Revista Ibero-Americano de estratégia, v. 10, n 3, p. 126-146, 2011.

CARVALHO, I.C.M. Educação Ambiental: a formação do sujeito ecológico. São Paulo: Cortez, 2008.

DIAMOND, J. The mysterious origin of AIDS. Natural History, v. 101, n. 9, p. 25-9, 1992.

DUARTE, I.S. Impactos ambientais da produção de carne para consumo humano: a indústria da carne na contramão da tutela constitucional do meio ambiente. 2008. Dissertação (Mestrado em Direito) - Universidade Federal de Pernambuco. 117f., 2008. 
EISLER, M.C.; LEE, M.R.F.; TARLTON, J.F.; MARTIN, G.B.; BEDDINGTON, J.; DUNGAIT, J.A.L.; GREATHEAD, H.; LIU, J.; MATHEW, S.; MILLER, $\mathrm{H}$.; MISSELBROOK, T.; MURRAY, P.; VINOD, V.K.; SAUN, R.V.; WINTER, M.; Agriculture: Steps to sustainable livestock. Nature, v. 507, p. 32-34, 2014.

FEYERABEND, P. Contra o Método, 2. ed. São Paulo: Unesp, 2011.

FOOD AND AGRICULTURE ORGANIZATION (FAOSTAT). Food and agriculture data, c2013. Disponível em: <http://www.fao.org/faostat/en/\#home $>$. Acesso em: 3 jun. 2020.

GE, M.; LEVIN, K.; FRIEDRICH, J. Tracking Progress of the 2020 Climate Turning Point. Washington D.C.: World Resources Institute, 2019.

GONÇALVES, E.S.; SILVA, J.M.B.; PAVESI, T.; MOREIRA, J.C. A importância da determinação analítica de intermediários reativos e de seus produtos de reações com biomacromoléculas: uma mini revisão. Química nova, v. 37, n. 2, p. 317-322, 2014

GRACE, D.; MUTUA, F.; OCHUNGO, P.; KRUSKA, R.; JONES, K.; BRIERLEY, L.; LAPAR, L.; SAID, M.; HERRERO, M.; PHUC, P.D.; THAO, N.B.; AKUKU, I.; OGUTU, F. Mapping of Poverty and Likely Zoonoses Hotspots. International Livestock Research Institute, c2012. Disponível em: $<$ https://cgspace.cgiar.org/bitstream/handle/10568/21161/ZooMap July2012 final.pdf> Acesso em: 14 abr. 2020.

JACKSON, C.R.; FEDORKA-CRAY, P.J.; BARRETT, J.B.; LADELEY, S.R. Effects of tylosin use on erythromycin resistance in enterococci isolated from swine. Applied Environmental Microbiology, v. 70, n. 7, p. 4205-4210, 2004.

JOY, M. Porque amamos os cachorros, comemos porcos e vestimos vacas: uma introdução ao carnismo. São Paulo: Cultrix, 2014.

KATAOKA, A.M.; FERNANDES, C.T.; NOGUEIRA, J.F.F.; MORAES, M.M. A complexa relação entre consumo de carne e a educação ambiental. In: MORAES, J.L.; CAMPOS, M.A.T. A educação ambiental sob o luar das araucárias. Curitiba: Appris, 2019.

KOLBER, T. A sexta extinção: uma história não natural. 1. ed. Rio de Janeiro: Intrinsceca, 2015.

LEDEBERG, J.; SHOPE, R.E.; OAKS S.C. Emerging infections: microbial threats to health in the United States. Washington: National Academy Press, 1992.

MALHEIROS, P.; SILVA, P. Contaminação bacteriológica das águas subterrâneas da região oeste de Santa Catarina. Revista do instituto do Adolfo Lutz, v. 68, n. 2, p. 18-34, 2009.

MARQUES, L. A pandemia incide no ano mais importante da história da humanidade: Serão as próximas zoonoses gestadas no Brasil? Unicamp, c2020. Disponível em < https://www.unicamp.br/unicamp/noticias/2020/05/05/pandemiaincide-no-ano-mais-importante-da-historia-da-humanidade-serao-proximas $>$. Acesso em: 19 abr. 2020.

MINISTÉRIO DO MEIO AMBIENTE (MMA). Consumo sustentável: Manual de educação. Brasília: Consumers International/MEC/IDEC, 2015.160 p. 
MORAES, M. C. Da Epistemologia da Complexidade à Docência Transdisciplinar. Transdisciplinaridade e Educação do Futuro. Brasília: Cátedra UNESCO de Juventude, Educação e Sociedade, p. 135-165, 2019.

MORIN, E. Introdução ao pensamento complexo. Porto Alegre: Sulina, 2015.

MORIN, E. O método 1: da natureza a natureza. Porto Alegre: Sulina, 2013.

MORIN, E. Os sete saberes necessários a educação do futuro. 2. Ed. São Paulo: Cortez, 2011.

NASA, 2020. GISS Surface Temperature Analysis (GISTEMP), version 4. NASA Goddard Institute for Space Studies. Disponível em: <data.giss.nasa.gov/gistemp/>. Acesso em: 18 abr. 2020.

NELLEMAN, C.; MACDEVETTE, M.; MANDERS, T.; EICKHOUT, B.; SVIHUS, B.; PRINS, G.A.; The environmental food crisis the environment's role in averting future food crises: a UNEP rapid response assessment, c2009. Disponível em: $<$ http://old.unep-wcmc.org/medialibrary/2010/09/07/51d38855/FoodCrisis.pdf> Acesso em: 27 abr. 2020.

NEUMANN, P.; ANTONIO, J. M.; KATAOKA, A. M. K. Identidade Terrena e Educação Ambiental Complexa: reflexões a partir de uma experiência pedagógica no Brasil. Revista Pedagógica, v. 21, p. 577-596, 2019.

NICOLESCU, B. O Manifesto da Transdisciplinaridade. São Paulo: Triom, 1999.

NICOLESCU, B. Transdisciplinaridade: uma esperança para a humanidade. In: DRAVET, F.; P., FLORENT; C., J.; CASTRO, G. (Orgs.). Transdisciplinaridade e Educação do Futuro. Brasília: Cátedra UNESCO de Juventude, Educação e Sociedade, p. 13-18, 2019.

PAULINO, M. A ameaça do desmatamento. Revista de informações e debates do Instituto de Pesquisa Econômica Aplicada, v. 84, n. 12, p. 1-16, 2015.

PECL, G.; ARAUJO, M. B.; BELL, J. D.; BLANCHARD, J.; BRONEBRAKE, T. C. Biodiversity redistribution under climate change: Impacts on ecosystems and human well-being. Science, v. 355, p. 1-9, 2017.

PENA, G.O. Doenças infecciosas e parasitárias: aspectos clínicos, de vigilância epidemiológica e de controle - guia de bolso. Brasília: Ministério da Saúde: Fundação Nacional de Saúde, 220 p.,1998.

PINHEIRO, B.G.; DE-LUCA, M.M.M.; VASCONCELOS, A.C. Conexões políticas nas maiores companhias listadas na BM\&FBOVESPA. Revista eletrônica de administração, v. 84, n. 2, p. 394-428, 2016.

RIPPLE, J.W.; WOLF, C.; NEWSOME, T.M.; GALETTI, M.; ALAMGIR, M.; CRIST, E.; MAHMOUD, M.I.; LAURANCE, W.F. World Scientists' Warning to Humanity: A Second Notice. BioScience, v. 67, n. 12, p. 1026-1028, 2017.

SAPKOTA. A.R.; HULET, R.M.; ZHANG, G.; MCDERMOTT, P.; KINNEY, E.; SCHWAB, K.J.; JOSEPH, S.W.; Lower prevalence of antibiotic-resistant enterococci on U.S. conventional poultry farms that transitioned to organic practices. Environmental Health Perspectives, v. 119, p. 1622-1628, 2011. 
SCHMIDINGER, K.S. Including CO2 implications of land occupation LCAs -method and example for livestock products. The International Journal of Life Cycle Assessment, v. 17, n. 1, p. 962-972, 2012.

SCHUCK, C.; RIBEIRO, R. Comendo o planeta: impactos ambientais da criação e consumo de animais. 3 ed. Curitiba: Vesper AMB, 2015.

SETTELE, J.; DÍAZ, S.; BRONDIZIO, E.; DASZAK, P. COVID-19 Stimulus Measures Must save Lives, Protect Livelihoods, and Safeguard Nature to Reduce the Risk of Future Pandemics. Plataforma intergovernamental sobre biodiversidade e serviços ecossistêmicos (IPBES), c2020. Disponível em: $<$ https://ipbes.net/covid19stimulus?fbclid=IwAR0RUfOUl9csjtcmx0yEDEghPeQkFwgZ4 kUSK4F-Mzp8LqnKUPwPr-2wIDM>. Acesso em: 20 abr. 2020.

SISTEMA DE ESTIMATIVA DE EMISSÕES DE GASES DE EFEITO ESTUFA (SEEG). Análise das emissões de GEE no Brasil (1970-2013) e suas implicações para políticas públicas. São Paulo: Observatório do Clima, 52 p., 2015.

WORLD ECONOMIC FORUM (WEF) How biodiversity loss is hurting our ability to combat pandemics, c2020. Disponível em: $<$ https://www.weforum.org/agenda/2020/03/biodiversity-loss-is-hurting-our-ability-toprepare-for-pandemics>. Acesso em: 28 abr. 2020. 